\title{
Preventing horticultural introductions of invasive plants: potential efficacy of voluntary initiatives
}

\author{
Jennifer W. Burt · Adrianna A. Muir · Jonah Piovia-Scott $\cdot$ Kari E. Veblen · \\ Andy L. Chang · Judah D. Grossman · Heidi W. Weiskel
}

Received: 5 July 2006/ Accepted: 3 January 2007 / Published online: 1 March 2007

(C) Springer Science+Business Media B.V. 2007

\begin{abstract}
Although prevention is the most costeffective way to avoid the enormous expenses associated with plant invasions, invasive plants continue to be imported as trade commodities for horticultural use. With very little government regulation of horticultural imports of invasive plants, efforts have turned toward fostering voluntary initiatives to encourage self-regulation by the horticulture trade. Our study takes the first step toward evaluating the potential success of these voluntary initiatives. We conducted a survey of nursery professionals to gauge their perceptions of invasive species, the role of the horticulture trade in invasive plant introductions, and their participation-potential and actual-in preventive measures outlined in the St Louis Voluntary Codes of Conduct for nursery professionals. We found nursery professionals to be highly aware of invasive
\end{abstract}

J. W. Burt $(\bowtie) \cdot$ K. E. Veblen · J. D. Grossman Department of Plant Sciences, University of California, Mail Stop 1, One Shields Avenue, Davis, CA 95616, USA

e-mail: jwburt@ucdavis.edu

A. A. Muir · J. Piovia-Scott

Section of Evolution and Ecology, University of California, One Shields Avenue, Davis, CA 95616, USA

A. L. Chang · H. W. Weiskel

Department of Environmental Science and Policy, University of California, One Shields Avenue, Davis, CA 95616, USA plants and to accept responsibility as a trade for horticultural introductions. Although only $7 \%$ of respondents had heard of the St Louis Voluntary Codes of Conduct, the majority (57\%) reported having participated in at least two of seven preventive measures, and most $(78 \%)$ reported willingness to engage in the majority of preventive measures. We found that several factors significantly predict increased participation in preventive measures, particularly awareness of invasive plants and involvement in trade associations. We also identified incentives and obstacles to participating in preventive behaviors, including "concern for the environment" and "lack of information," respectively. Our results suggest that participation in voluntary initiatives will improve through increased outreach, and we provide specific recommendations for improving participation in voluntary programs in the horticulture trade.

Keywords Horticulture - Invasive species · Nonmandatory programs · Nursery · Prevention . St Louis Declaration - Self-regulation · Survey · Voluntary codes of conduct

\section{Introduction}

Introductions of invasive species produce serious detrimental economic and environmental consequences (Vitousek et al. 1997; Wilcove et al. 1998; 
Mack et al. 2000; Pimentel et al. 2005), and scientific and public attention to invasive species has increased exponentially in the past 20 years (Rejmanek 2000; Reichard and White 2001, 2003). It has become overwhelmingly clear that prevention of initial introductions, rather than subsequent control or eradication, represents the most efficient and cost-effective approach to combat invasive species (Mack et al. 2000; NISC 2001; Leung et al. 2002). Yet the scientific community and public and private institutions have dedicated substantially more attention and resources to eradication and control (Fig. 1; Leung et al. 2002; Puth and Post 2005). This is in part due to the fact that control and eradication efforts often fall into the realm of crisis management: responses to already widespread and urgent environmental threats. Alternatively, to prevent introductions of invasive species before they cause any harm generally requires restricting commerce and incorporating future external costs into decision-making processes (Barbier and Knowler 2006). Although meager regulations are in place to prevent introductions (e.g., border inspections, container fumigation at ports, ballast water exchange programs) they are clearly not sufficient, and the sheer magnitude of commerce further hinders prevention efforts.

Many invasive plants are inadvertently transported around the world as hitchhikers with seeds, soil or other products, while others are introduced intentionally as trade commodities (Mack et al. 2000; Pimentel et al. 2005). Although prevention of intentional introductions appears more tractable than prevention of inadvertent introductions, successful approaches must go beyond the ongoing development of reliable risk assessment tools (Hulme 2003). Prevention of intentional introductions requires an understanding of the industries importing and selling invasive species and the political will to regulate importing practices, whether via government regulation or voluntary group initiatives. In the absence of external regulation, it is particularly important to assess the potential efficacy of selfregulation.

The horticulture trade, which is economically important and one of the fastest growing segments of US agriculture (Carman and Rodriguez 2004; Shields and Willits 2003; Hall et al. 2005; Jerardo 2005), is a principal pathway for intentional introductions of invasive plants (Reichard 1997; Reichard and White 2001). A large percentage of invasive plant species in the US have been deliberately imported for horticultural and landscaping purposes (Reichard 1997; Reichard and White 2001; Mack and Erneberg 2002; Bell et al. 2003; Pimentel et al. 2005). The horticulture trade benefits financially from novelty and diversity, and furthermore the most sought after species for horticultural importation often grow readily with little maintenance in the climates where they are introduced (Bell et al. 2003). Although the majority of plants imported for horticulture have proven non-invasive, many successful horticultural escapes have wreaked severe economic and environmental harm (Mack et al. 2000; Pimentel et al. 2005). Yet importation of invasive and
Fig. 1 Stages of the invasion process and corresponding management strategies. Our study focuses on prevention, the most costeffective but least studied approach to reduce impacts of invasive plants

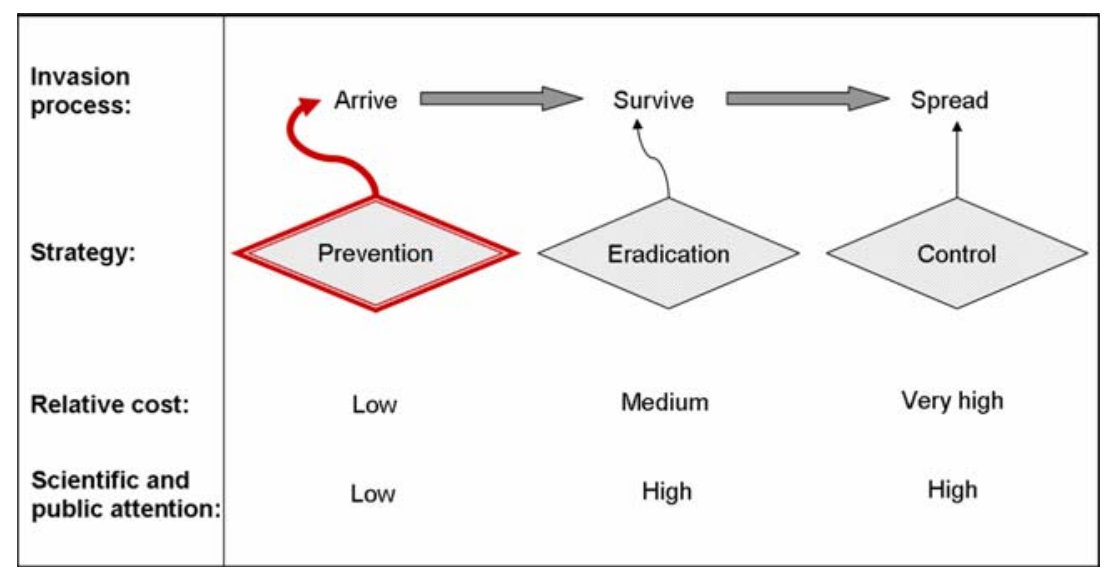


potentially invasive plants continues (Tschohl 2000; NRC 2002; D'Antonio et al. 2004). For example, purple loosestrife (Lythrum salicaria), available for sale as an ornamental plant in many states (Anderson 2004; Barbier and Knowler 2006), is associated with $\$ 45$ million of damage per year in the US, including control costs and loss of forage (ATTRA 1997; Pimentel et al. 2000).

Recognition of the horticultural trade as a major pathway for introductions of invasive plant species has increased steadily (Reichard and White 2001; Pimentel et al. 2005); however, laws specifically addressing the introduction and exchange of potentially invasive plants via the horticultural trade remain inadequate (Mack et al. 2000; D'Antonio et al. 2004). Most recent efforts to prevent the introduction of invasive plants center on voluntary self-regulation of the horticulture trade (Bell et al. 2003; Reichard 2004; Reichard et al. 2005). Government and industry increasingly prefer self-regulation as an important alternative to imposing higher-level rules and regulations (Harrison 1999; Khanna 2001; Alberini and Segerson 2002).

Self-regulation by the horticulture trade to reduce possible introductions of invasive plants has the potential to be successful for several reasons. First, the horticulture trade deals primarily in non-essential commodities, and in both ornamental landscaping and erosion control, equally appealing non-invasive alternative plants can substitute for particular invasive plants. Second, close contact with consumers and high public visibility of the horticulture trade also increase the potential for self-regulation within this industry, as these characteristics can increase business benefits associated with cultivating an environmentally responsible business image (Videras and Alberini 2000; Khanna 2001). However, consumer behavior and choice is integral to fostering any environmentally responsible stance adopted by industry. Finally, the credible threat of increased government regulation of horticultural imports (e.g., APHIS 2004) presumably increases pressure on the horticulture trade to proactively adopt voluntary initiatives.

The last decade has seen a number of coalitions organized with the aim of creating and promoting voluntary initiatives to prevent horticultural introductions of invasive plants. The most widely recognized initiative is the St Louis Declaration and Voluntary Codes of Conduct, initially drafted in 2001 and ratified in 2002 by a diverse group of stakeholders from across the country that included non-profit organizations, trade representatives, and scientists (Fay 2001; Baskin 2002). These Codes of Conduct for nursery professionals, government, the gardening public, landscape architects, and botanic gardens received wide publicity (Fay 2001, 2002; Baskin 2002). Some 42 entities, including many national nursery trade organizations, have endorsed these Codes (CPC 2006). The preventive measures outlined in the Codes include actions such as monitoring new species for invasiveness and forgoing sales of known invasive plants.

Non-mandatory initiatives have emerged as a currently popular approach to prevention, receiving support both within and outside the horticulture trade. Regionally focused coalitions working toward voluntary initiatives for prevention of invasive plant introductions include major efforts in Florida (FLEPPC 2001), North Carolina (Reichard and White 2001), Massachusetts (MIPAG 2005; Reichard et al. 2005), and California (Connick and Gerel 2005).

Despite this optimism and effort, it remains unclear whether voluntary initiatives, alone, can ultimately prove effective in preventing the introduction of invasive plants (Caton 2005; Reichard et al. 2005). Such programs carry a risk of producing false industry and public assurance while failing to actualize the intended changes (Harrison 1999; Potoski and Prakash 2002; Rivera and de Leon 2004). Since the current political climate increasingly favors and proposes selfregulation, it becomes especially important to identify the social factors that will affect industry participation in voluntary programs (Potoski and Prakash 2002).

The US horticulture trade is relatively decentralized, thus success of a voluntary initiative may ultimately depend on the actions of individual nursery professionals. How these individuals perceive both the environmental problem addressed by a voluntary initiative and their own potential role in mitigating the problem is likely to affect participation (Manzo and Weinstein 1987; Lubell 2004). Specific factors expected to affect 
participation of nursery professionals in voluntary initiatives include their familiarity with recommended actions, their perceptions of the problem of invasive plant introductions, and their acknowledgment of the horticulture trade's role in this problem. In other industries, business characteristics also seem to be important predictors of behavior and of acceptance of voluntary initiatives: businesses adopt voluntary initiatives more often when they are larger, more profitable, and more closely tied with consumers (Khanna 2001; Alberini and Segerson 2002; Anton et al. 2004; Rivera and de Leon 2004). Involvement in trade associations may also be an important predictor of participation in voluntary initiatives, as involvement in trade associations may indicate the degree to which a nursery professional is connected with the nursery community. Finally, understanding factors associated with participation in voluntary initiatives requires parallel understanding of incentives and obstacles to their adoption. Incentives to adopt voluntary initiatives may include concern for the environment, consumer pressure, or avoidance of government regulations (Khanna 2001; Alberini and Segerson 2002; Anton et al. 2004; Lubell 2004). Obstacles to adoption may include perceived economic or time constraints, or the lack of tools and infrastructure to implement voluntary measures (Khanna 2001; Lubell 2002, 2004; Alberini and Segerson 2002).

Here, we consider an important aspect of prevention of horticultural introductions of invasive plants: the behavior of individual horticultural wholesalers and retailers. We present results of a survey of nursery professionals conducted to determine levels of participation in preventive measures outlined in the St Louis Voluntary Codes of Conduct for nursery professionals, and to examine factors motivating and/or discouraging participation in voluntary initiatives.

\section{Methods}

Survey objectives and hypotheses

Our survey was designed with the following objectives: (1) assess the perceptions of nursery professionals on various aspects of the topic of invasive plant introductions via the horticulture trade; (2) determine levels of participation in voluntary preventive measures; (3) examine the extent of relationships between perceptions, business characteristics, and participation in voluntary preventive measures; and (4) investigate which incentives and obstacles emerge as most important to nursery professionals.

For the third objective, we tested several specific hypotheses pertaining to factors predicting participation in preventive measures. First, we expected that nursery professionals who perceive invasive plants as an important environmental problem would be more likely to engage in preventive behaviors. Second, we expected that nursery professionals who perceive the horticulture trade to be responsible for invasive plant introductions would be more likely to participate in preventive measures. Finally, we anticipated that participation rates would correlate with several business characteristics, including public visibility, business size, and involvement in trade associations.

Studies of other voluntary environmental programs in industry have highlighted relationships between several business characteristics and participation rates (Videras and Alberini 2000; Khanna 2001; Alberini and Segerson 2002; Anton et al. 2004). Based on patterns observed in other industries, we hypothesized that respondents from businesses that are less visible to the consumer public (wholesale, or grower nurseries) would be less likely to participate in preventive measures than retail, or non-grower counterparts, and that respondents from larger businesses would be more likely to participate in preventive measures than those from smaller businesses. We also hypothesized that respondents with greater reported involvement in trade associations would be more likely to participate in preventive measures.

Study population and data collection

Our study population consisted of San Francisco Bay Area wholesale and retail nurseries. Wildlands in this geographic region are valued for their high endemic plant diversity and have become highly invaded by non-native plants. Many of the plant species invading these wildlands are still sold 
commercially and are thus available for further dispersal via regional nurseries (Connick and Gerel 2005; J.W. Burt, pers obs).

We assembled the population of potential survey respondents by performing a keyword search using the AT\&T (formerly SBC) and Bellsouth Internet directories for wholesale and retail horticultural nurseries in the nine San Francisco Bay Area counties (Alameda, Contra Costa, Marin, Napa, San Francisco, San Mateo, Santa Clara, Solano, and Sonoma). We excluded highly specialized nurseries (e.g., nurseries selling only succulents, roses, etc.), generating a list of over 400 nurseries.

The survey was conducted in March 2005. We called nurseries in random order from the generated list until we had completed at least 50 surveys. To reach our goal of 50 respondents, we called a total of 207 entries. Of these 207 entries, 85 were removed from our sample population (leaving 122) because they were either out of business, had an incorrect number listed, did not answer the phone, did not speak English, or were highly specialized. Of the remaining 122 nurseries carrying a general selection of outdoor plants, 48 additional businesses were excluded (leaving 74) because we were unable to reach a suitable participant (an owner, manager, or employee in charge of plant purchasing). Finally, of the 74 potential participants who we successfully contacted and gave the opportunity to take the survey, 54 respondents took the survey, for a response rate of $73 \%$.

There is potential for some bias in our survey results because respondents who were more difficult to reach were somewhat less likely to be surveyed. To offset this potential bias, we conducted survey calls during slow periods for business (e.g., early morning) and made great efforts to schedule appointments convenient for potential respondents. We were thus able to include many respondents regardless of their workload. Potential respondents were asked only to participate in a survey of nursery professionals sponsored by a group at UC Davis and were not otherwise informed of the content or purpose of the survey before taking the survey. Thus, the response rate was not biased by the topic of the survey.
The telephone survey consisted of 25 multipart, closed-end questions with opportunity for further comment afterward. The survey was designed to minimize response bias, with survey topics progressing from general to specific as the survey proceeded. For example, information on the St Louis Voluntary Codes of Conduct was introduced only after respondents had answered questions about their potential and actual engagement in preventive behaviors. The complete survey is contained in the Appendix. Specific questions used in statistical analyses are described in detail below.

\section{Variable construction}

For several of our analyses, the dependent variable was respondents' level of participation in seven preventive measures (based on the St Louis Voluntary Codes of Conduct for nursery professionals and listed in Table 1). Our "participation" metric for each respondent consisted of the number of preventive measures (from 0 to 7 ) in which they reported they "have engaged."

We employed combined metrics to construct several of our predictor variables in order to take advantage of complementary survey questions and to incorporate nuances between questions. We rated respondents' perception of invasive plants as an environmental problem ("awareness") according to their responses to two related survey questions. Respondents scored their agreement with two statements- "invasive plants have a negative impact on native plants and animals" and "invasive plants are an important environmental concern", - on a 5-point Likert scale, with 5 equivalent to "strongly agree" and 1 equivalent to "strongly disagree." We used the sum of these scores as our "awareness" metric.

Similarly, we rated perceived responsibility of the horticulture trade for invasive plant introductions ("responsibility"), by combining responses to two survey questions. The first assessed agreement with the statement "the horticulture trade plays a role in the introduction of invasive plants" using a 5-point Likert scale as described above. The second question called on respondents to assign responsibility scores (on a scale of 1-5, with $5=$ "most responsible") for prevention of 
Table 1 Preventive measures adapted from the St Louis Voluntary Code of Conduct for nursery professionals, with percentage of respondents reporting that they "have engaged" or "would engage" in each measure

\begin{tabular}{lcc}
\hline Preventive measures & $\begin{array}{c}\text { \% reporting } \\
\text { "have engaged" }\end{array}$ & $\begin{array}{c}\text { \% reporting } \\
\text { "would engage" }\end{array}$ \\
\hline (1) Evaluate horticultural plants for whether they are likely to become & 35 & 31 \\
$\quad$ invasive & 31 & 30 \\
(2) Monitor plants to assess whether they may be invasive & 35 & 41 \\
(3) Interact with experts to determine which plants are or might become & & 56 \\
$\quad$ invasive & 26 & 6 \\
(4) Interact with experts to determine alternatives to plants that might be & & 46 \\
(5) Try to breed alternatives to invasive plants & 39 \\
(6) Phase out plants that nursery associations, scientists, and other experts & & 20 \\
(7) Encourage customers to use non-invasive plants & 69 &
\end{tabular}

The remaining respondents indicated that they "have not and would not" engage in each activity or that it is "not applicable",

horticultural introductions of invasive plants to each of seven groups (consumers, retailers, wholesalers, growers, policy makers, government agencies, and scientists). For this second question, we calculated the average of responsibility scores assigned to the three horticultural groups (retailers, wholesalers, and growers). We then summed this average horticultural responsibility score with the response to the first responsibility question to create the horticultural "responsibility" metric.

We also used four business characteristics as independent variables. Nursery size was taken directly from a question on the survey in which we asked respondents if they considered their nursery to be small, medium, or large relative to other nurseries in the region. We defined respondents that classified their nurseries as primarily retail or both retail and wholesale as "retail," while those who classified their nurseries only as wholesale were considered "wholesale." We classified nurseries that grew any of their own plants as "growers." We determined involvement in trade associations for each respondent by their level of activity within five trade associations (listed in Appendix, Question 10). For each trade association, respondents were given a point for each of the following attributes: having heard of the organization, being a member, reading the association's literature, and attending meetings. The total (summed) scores of all five trade associations constituted the "involvement" metric.
Statistical analyses

We analyzed how awareness of invasive plants, perceived responsibility for invasive plant introductions, and business characteristics relate to participation in preventive measures using a general linear model (PROC GLM, SAS version 8.0, SAS Institute, 1999). Data met parametric normality and homoscedasticity assumptions. The linear model relating awareness, responsibility, and business characteristics to participation in preventive measures was based on the a priori hypotheses described earlier. In order to test the robustness of conclusions derived from that model, we conducted a basic model selection procedure to determine if any interactions between independent variables should be included. No interaction terms were selected for inclusion based on a stepwise procedure utilizing the Schwarz-Bayesian Information Criterion (PROC GLMSELECT, SAS version 9.0, SAS Institute, 2006). Inclusion of the best candidate interaction terms (awareness $\times$ responsibility and type $x$ size) did not change the qualitative results of the model so we present the results from the a priori model without any interaction terms.

We ran a parallel analysis using "willingness to participate" as the dependent variable, where "willingness" was scored as the sum of "have engaged" or "would engage" responses for the seven preventative measures. This model did not 
have significant predictive power (overall model $\left.p=0.41, R^{2}=0.15\right)$ and is not discussed further.

We conducted an ANOVA to assess whom respondents indicated as most responsible for preventing invasive plant introductions. Using individual respondents as a class variable, we compared responsibility levels assigned to each of seven groups (retailers, wholesalers, growers, policy makers, scientists, government agencies, and consumers). To test the hypothesis that respondents assigned a different responsibility level to horticultural groups (retailers, wholesalers, and growers) than to non-horticultural groups (policy makers, scientists, government agencies, and consumers) we performed an a priori contrast (Gotelli and Ellison 2004, p 339). After transformations failed to resolve problems of lack of homoscedasticity, we used a variance-weighted ANOVA for these tests (PROC GLM, SAS version 8.0, SAS Institute, 1999).

\section{Results}

Characteristics of nurseries in the San Francisco Bay Area

A majority of respondents $(72 \%)$ characterized their nurseries as "retail" while $20 \%$ characterized their nurseries as "wholesale," and 8\% answered "both." The distribution of nursery sizes is relatively even: $41 \%$ of respondents described their businesses as "small," $31 \%$ as "medium," and $28 \%$ as "large." About half $(52 \%)$ of respondents declared membership in trade associations. The California Association of Nurseries and Garden Centers registered as the most popular trade association among the respondents by far; however, only $50 \%$ of respondents reported any involvement (reading literature, attending meetings, or membership) with this organization. Over half of respondents (57\%) stated that their nurseries grow at least some portion of the plants they sell, and relatively few (9\%) indicated that they engage in plant breeding.

Perspectives on invasive plants and responsibility for prevention

Awareness of the invasive plant problem was high. All survey respondents $(100 \%)$ had heard the term "invasive species." An overwhelming majority (93\%) agreed that "invasive plants are an important environmental concern," while $89 \%$ of respondents agreed that "invasive plants have a negative impact on native plants and animals." Respondents also acknowledged that the horticulture trade is responsible for some invasive plant introductions. Most respondents $(81 \%)$ agreed that "nurseries sell invasive plants or plants that may become invasive" and $82 \%$ agreed that "the horticulture trade plays a role in the introduction of invasive plants." Furthermore, respondents indicated that horticultural groups were more "responsible for preventing plant invasions via the horticulture trade" than non-horticultural groups (Fig. 2; planned contrast from weighted ANOVA, $F=36.56, \quad d f=1, \quad p<0.0001)$, with growers assigned the highest responsibility score and consumers assigned the lowest responsibility score.

\section{Participation in voluntary initiatives}

Very few survey respondents (7\%) knew of the St Louis Voluntary Codes of Conduct. Respondents reported having participated in an average of 2.4 out of 7 preventive measures. Table 1 lists the seven preventive measures and the percent of respondents reporting that they "have" engaged or "would" engage in each measure, respectively. About $83 \%$ of respondents reported having participated in at least one preventive measure, whereas nearly all (98\%) respondents reported that they were at least willing to participate in one or more measures (Fig. 3). However, the percentage of respondents reporting participation in at least a particular number of preventive measures quickly declines as the cumulative number of measures increases (Fig. 3). No respondents reported participation or willingness to participate in all seven preventive measures.

A little more than half $(52 \%)$ of respondents indicated that learning of the existence of the St Louis Voluntary Codes of Conduct during the survey made them more likely to participate in the preventive measures outlined in this initiative. 


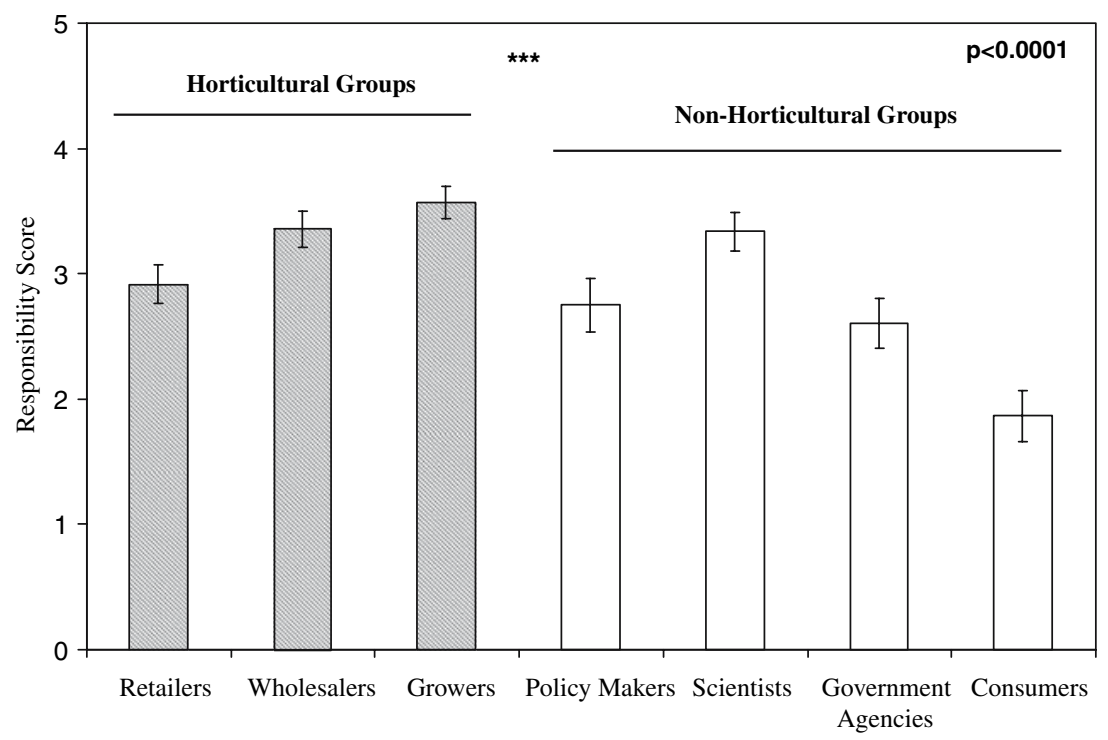

Fig. 2 Responsibility for prevention of invasive plant introductions via the horticulture trade. Respondents assigned responsibility scores to each group on a scale from 1 to 5 , with 5 as most responsible and 1 as least responsible. Responsibility scores assigned to all horticul-

Relating perceptions, business characteristics, and preventive behaviors

The survey found a significant relationship between perceptions, business characteristics, and participation in preventive measures, with the tural groups combined (shaded bars) were significantly greater than scores assigned to non-horticultural groups (unshaded bars; a priori contrast in variance-weighted ANOVA; $p<0.0001)$. Error bars denote standard error of the mean

model explaining $27 \%$ of the variation in reported participation. The results of the linear model are presented in Table 2. Respondents with a higher awareness of the invasive plant problem reported significantly greater participation in preventive measures. However, we found no support for
Fig. 3 Percentage of respondents reporting participation ("have engaged") and willingness to participate ("have engaged" or "would engage") in at least each number of preventive measures. For example, $39 \%$ of respondents reported that they have engaged in at least three preventive measures, and $85 \%$ reported that they have or would engage in at least three measures. The preventive measures are listed in Table 1

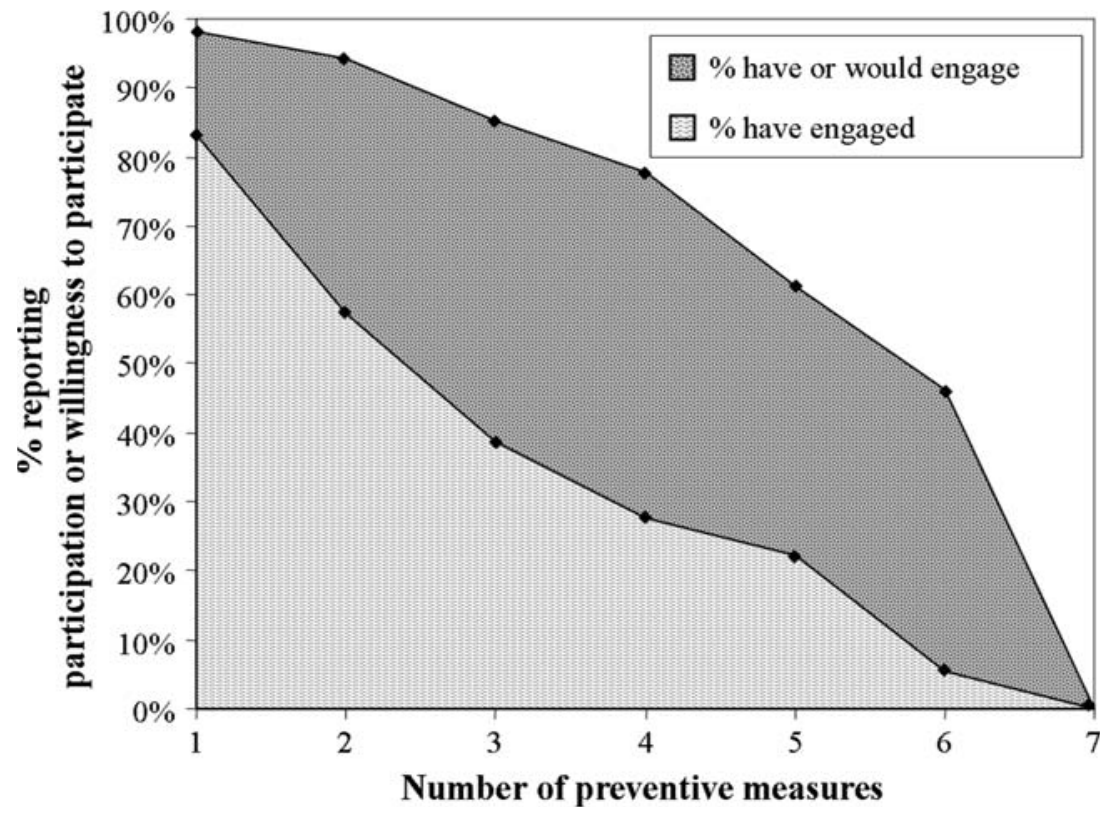


Table 2 Results of linear model examining business characteristics, perception of invasive species problem, and perception of the horticulture trade's responsibility (for introductions of invasive plants) as predictors of participation in preventive measures

\begin{tabular}{llll}
\hline & $d f$ & $F$ & $p$ \\
\hline Model & 7 & 2.27 & $\mathbf{0 . 0 4 7}$ \\
Involvement in trade associations & 1 & 6.24 & $\mathbf{0 . 0 1 6}$ \\
Size & 2 & 2.19 & 0.125 \\
Retail/wholesale & 1 & 2.57 & 0.116 \\
Grower/non-grower & 1 & 5.80 & $\mathbf{0 . 0 2 0}$ \\
Awareness of the invasive species problem & 1 & 4.26 & $\mathbf{0 . 0 4 5}$ \\
Perception of horticulture trade's & 1 & 0.06 & 0.810 \\
$\quad$ responsibility & & &
\end{tabular}

Factors are described in detail in the text. Statistically significant values $(p<0.05)$ are shown in bold text

our hypothesis that respondents' perception of responsibility would positively correlate with participation in preventive measures, as the relationship between the responsibility metric and reported participation was non-significant. Respondents who reported greater involvement with trade associations reported participating in significantly more preventive measures. Nursery type (retail vs. wholesale) and size were nonsignificant predictors of participation in preventive measures. "Growers," however, reported significantly higher participation than non-growers.

Incentives and obstacles

When asked which of a list of factors (Table 3) encouraged participation in preventive measures, respondents most commonly cited "concern for the environment" (91\% of respondents) and "cultivating a green business image" (75\%). Respondents most often cited "lack of information" (66\% of respondents) as an obstacle to participation in preventive behaviors, followed by "limited personnel" (60\%) and "too time-consuming" (58\%).

\section{Discussion}

Our results provide some basis for optimism toward the potential widespread adoption of voluntary initiatives to prevent further horticultural introductions of invasive plants. We found that most nursery professionals in our study region are generally aware of invasive plants and their
Table 3 Incentives and obstacles to participation in preventive measures outlined in the St Louis Voluntary Codes of Conduct, ranked by percentage of respondents reporting each factor

\begin{tabular}{ll}
\hline & $\%$ cited \\
\hline Incentives & 91 \\
Concern for the environment & 75 \\
Cultivating a green business image & 70 \\
Consumer demand & 53 \\
If other nurseries were doing these activities & 45 \\
Employee pressure & 42 \\
Preventing government regulations & \\
Obstacles & 66 \\
Lack of information & 60 \\
Limited personnel & 58 \\
Too time-consuming & 38 \\
Too expensive & 36 \\
Lack of incentive & 28 \\
Other environmental concerns are more & \\
important & 19 \\
Lack of interest & 15 \\
Engaging in these activities won't help to \\
prevent invasions & \\
Other nurseries aren't doing these activities & 11 \\
\hline
\end{tabular}

associated environmental impacts, indicating that awareness of the problem is not a primary factor limiting the adoption of preventive practices in this region. Respondents also displayed widespread acceptance of the idea that the horticulture trade should shoulder responsibility for preventing invasive plant introductions, and, surprisingly, considered consumers to be the group least responsible for prevention. We consider these findings encouraging for current and future efforts promoting selfregulation of the horticulture trade.

Most nursery professionals surveyed participate in at least some preventive measures, but few participated in the majority of measures. Many respondents did express willingness to engage in the majority of the measures, however (Fig. 3). Thus, while participation in comprehensive preventive measures is not currently widespread, the survey indicates a great deal of nominal participation and existing potential for future, more efficacious participation.

Predictors of participation in preventive measures

Our analyses indicate that respondents' awareness of invasive plants-but not perception of 
responsibility of the horticulture trade-functions as a predictor of reported participation in preventive measures. Although most respondents indicated that they thought the horticulture trade should be held responsible for prevention, the acceptance of responsibility does not appear to directly motivate modification of nursery practices.

We found involvement in trade associations to be a significant predictor of participation in preventive measures, supporting our presumption that nursery professionals who are involved in trade associations may identify more closely with the nursery community and share greater awareness of current issues in horticulture, perhaps via information directly disseminated by trade associations. It also may be that individuals with higher involvement in trade associations share a greater personal motivation to participate in group endeavors.

Despite potentially lower visibility to the consumer public, "grower" businesses showed a significantly greater tendency to engage in preventive measures. Several of the preventive measures may be especially applicable to grower businesses, which may partly explain this trend. Perhaps more surprising, we did not detect any differences in behavior between respondents from wholesale and retail nurseries (less and more visible to the public, respectively) or among respondents from different size nurseries. This may underscore the nature of the horticulture trade as a diffuse industry made up of many individuals working autonomously; business size and visibility to consumers may not enter into decisions as much as beliefs and personal motivation.

Incentives and obstacles to prevention

The results of this study highlight incentives and obstacles that can be addressed in order to increase the participation of nursery professionals in preventive measures. Notably, the cited incentives rank in an order that emphasizes a strong environmental ideology and de-emphasizes purely business-related incentives (Table 3). "Concern for the environment" ranked by far as the topcited incentive, whereas all of the purely business- related incentives ranked lowest. Similarly, all topcited obstacles pertained to feasibility of participation, while respondents least cited belief-related obstacles (Table 3). These results further support the relationship we have detected between awareness and participation, and indicate that nursery professionals in our study region claim a strong environmental ideology as a significant motivator of their actions. Assuming respondents answered true to their beliefs, these results also indicate a population willing to modify behaviors to improve environmental performance.

Respondents most often cited "lack of information" as an obstacle to participation in preventive measures. However, our study suggests that nursery professionals do not lack general awareness of invasive species. Rather, nursery professionals lack more detailed information, presumably including essentials such as species-specific evaluations of invasiveness and practical guidelines for implementing preventive measures. Certainly our survey indicates that nursery professionals lack information regarding the St Louis Voluntary Codes of Conduct. We consider this an encouraging harbinger for recent voluntary initiatives because dissemination of information can improve substantially from both inside and outside the trade. Therefore this information gap may prove easier to overcome than other cited obstacles, such as "limited personnel" and "too time-consuming."

Conclusions and implications for voluntary initiatives in the horticulture trade

It commands attention that even in a voluntary program with high purported participation and publicity, the actual level of prevention achieved by each participant can prove very low (Alberini and Segerson 2002; Rivera and de Leon 2004). This has been documented for a regional effort toward voluntary self-regulation of the horticulture trade in the state of Florida, in which a coalition between advocacy groups and trade associations resulted in the mutual agreement to urge discontinued sales of 45 invasive plant species in 2001 (FLEPPC 2001). However, a recent study (Caton 2005) finds that this effort has not attained its intended goal—several years later 
the majority of "blacklisted" species remained openly retailed, and in fact the number of nurseries carrying at least one of the blacklisted species substantially increased. Although in some regards this effort had some positive outcomes, this example highlights how even a very highly endorsed voluntary initiative can suffer from low participation rates and efficacy because of individual choices.

In general, our survey results indicate that there is some cause for optimism for voluntary self-regulation of the horticulture trade. Ordinary nursery professionals in the San Francisco Bay Area show high levels of awareness of invasive species issues, readiness to accept responsibility as a trade for horticultural introductions of invasive plants, and willingness to participate in many of the preventive business practices outlined in the St Louis Voluntary Codes of Conduct for nursery professionals. Whether they will participate to the extent that would be required to effectively curtail introductions of horticultural invasives will depend on whether the identified obstacles, especially a lack of information, can be overcome. It will also depend on the motivation of individual nursery practitioners, some of whom did express refusal to participate in the majority of preventive measures. It may well be that if, ultimately, the intended goals of voluntary codes of conduct cannot be achieved in this particular population of nursery professionals, success at a broader scale is also unlikely.

The results of our study show that ineffective information dissemination and lack of outreach represent severe limiting factors for the success of voluntary efforts to prevent horticultural introductions of invasive plants. Because our study region has a reputation for environmental activism, we anticipated this region's nursery professionals would surpass the national norm in having heard of the St Louis Voluntary Codes of Conduct and in having engaged in the measures outlined therein. We found, however, that very few survey respondents had heard of the St Louis Voluntary Codes of Conduct, a remarkable result given that the Codes had been in circulation for 4 years and had received endorsements from many national organizations (Fay 2001, 2002; Baskin 2002; CPC 2006).
Although involvement with trade associations was a significant predictor of participation in preventive measures, in general our respondents were not highly involved with trade associations; thus information circulated through trade associations may not reach most nursery professionals. Therefore, we propose popular horticultural references as a more promising avenue of outreach. Specifically, Sunset Western Garden Book, a principal reference cited by $72 \%$ of respondents who make their own plant labels, could prove an effective conduit in the western US (Brenzel 2001). We suggest that incorporating an invasiveness rating for common horticultural species in such references can become an effective means of curbing sales and escapes of invasive plants at all levels, from commercial nurseries to the individual consumer. Due to the public lack of knowledge of species-specific invasiveness, however, scientists will need to become more involved in supplying clear and accessible information.

In conclusion, we recommend the following actions to increase participation in voluntary initiatives to curb horticultural introductions of invasive plants.

(1) Increase outreach for the St Louis Voluntary Codes of Conduct. Very few nursery professionals surveyed had heard of the Codes but many stated that learning of the codes makes them more likely to participate in the measures outlined therein.

(2) Provide clear and accessible information to nursery professionals that will aid with participation in prevention, such as information on species invasiveness and alternative, non-invasive species. Nursery professionals appear to lack specific information needed to implement preventive measures. Furthermore, our results suggest that increased awareness of the issue of horticultural invasives is positively associated with reported participation in preventive measures.

(3) Employ additional information pathways, such as existing popular gardening references, to directly disseminate information to those working within the trade. Information disseminated through trade associations alone may fail to reach many nursery professionals. 
Acknowledgements We are grateful to Teresa Sabol Spezio, Ted Grosholz, Kari Norgaard, John Randall, Sarah Connick, Terri Kempton, Doug Johnson, Sarah Reichard, Kevin Rice, Steve Schoenig, Carole Hom, Sharon Strauss, Rick Grosberg, Terri Williamson, and Beth Leger for invaluable insights and advice throughout this project. We are further indebted to Ted Grosholz, Brendon Larson, Mark Lubell, Kari Norgaard, Kevin Rice, Truman Young, George Williamson, and James Drake for critical readings of earlier drafts. This study benefited from advice on survey methodology and statistical analysis from Mark Lubell, Kari Norgaard, and Neil Willits. We also extend our thanks to the many nursery professionals who took the time to complete our telephone survey. Support for this project was provided by the National Science Foundation Biological Invasions IGERT program at UC Davis (NSFDGE \#0114432).

\section{Appendix: telephone survey}

1. How would you describe your business? (choices: chain, franchise, independent, or none of these)

2. Is your business primarily retail or wholesale?

3. In comparison to other nurseries in your region, do you consider your nursery to be small, medium, or large?

4. What is your job title and what are your primary duties?

5. Who makes up the majority of your customer base? (choices: gardeners, landscape contractors, other nurseries, other)

6. Does your business grow any of its own plants?

a. If yes: approximately what percentage of all the plants you sell do you grow on your own?

7. Does your business engage in plant breeding?

8. Does your business purchase any plant materials from suppliers outside of the US?

9. Does your business make any plant labels on site?

a. If yes: what sources do you use for label information?

10. I'm going to go through a list of organizations, for each one please describe your involvement-e.g., if you are a member or attend meetings. (choices: heard of them, member, read literature, attend meetings)
List of organizations: California Association of Nurseries and Garden Centers, Nursery Growers Association of California, American Nursery and Landscape Association, Garden Centers of America, North American Horticultural Supply.

11. Are there any other trade associations or organizations that you are involved with that I haven't mentioned? If so, please describe your involvement in these as well.

12. I'm going to go through a list of reasons. For each please say if it is very important, somewhat important, or unimportant for helping you decide which plants to sell.

List of reasons: aesthetic beauty, consumer demand, drought tolerance, easy to establish, easy to control, wholesale cost, readily available for purchase, native to California, disease and insect resistance

Are there any other considerations you take into account?

13. How do you find the amount of government regulation of the nursery trade: too little, too much, or just right? (choices: too little, just right, too much, don't know/not sure)
a. If too little: which areas so you think need tighter regulations?
b. If too much: which areas do you think need looser regulations?

14. Do you think the amount of government regulation of the nursery trade will change in the future?

15. Have you heard the term "invasive species"?

We will use the following definition of invasive species for the remainder of the survey: "A species that is introduced to an area where it is not native, and that establishes abundant populations in the wild which are difficult to control or eradicate."

16. Have you previously heard of weeds or invasive plants becoming problems in wildlands/natural areas? 
17. Do you think nurseries sell invasive plants or plants that may become invasive?

18. For each of the following statements, please rate yourself on a scale ranging from strongly agreeing to strongly disagreeing with that statement. (choices: strongly agree, agree, neither, disagree, strongly disagree, aren't sure)
a. Invasive plants have a negative impact on native plants and animals
b. Invasive plants are an important envi- ronmental concern
c. The horticulture trade plays a role in the introduction of invasive plants
d. The nursery trade should determine which plants will become invasive
e. Scientists/experts should determine which plants will become invasive
f. It is okay to sell plants known to be invasive

19. For each of the following activities I'd like you to answer whether you have or have not engaged in this activity. If you have not engaged in the activity, would you? (Choices: have, would, have not and would not, or not applicable)
a. Evaluate horticultural plants for whether they are likely to become invasive
b. Monitor plants to assess whether they may be invasive
c. Interact with experts to determine which plants are or might become invasive
d. Interact with experts to determine alter- natives to plants that might be invasive
e. Try to breed alternatives to invasive plants
f. Phase out plants that nursery associa- tions, scientists, and other experts deter- mine to be invasive
g. Encourage customers to use non-inva- sive plants

20. In general, for this set of activities as a whole, which of the following factors encourage you to engage in these activities?
a. Consumer demand
b. Cultivating a "green" business image
c. Concern for environment
d. If other nurseries were doing these activities
e. Employee pressure
f. Preventing government regulations
g. Other

21. In general, for this set of activities as a whole, which of the following factors significantly prevent you from engaging in these activities?
a. Too expensive
b. Too time-consuming
c. Limited personnel
d. Lack of information
e. Lack of interest
f. Lack of incentive
g. Other nurseries aren't doing these activities
h. Other environmental concerns more important
i. Engaging in these activities won't help prevent invasions
j. Other

22. Have you heard of the St Louis Voluntary Codes of Conduct for nursery professionals relating to invasive plants?

If yes:
a. Have you seen the codes?
b. Do you know generally what they say?
c. Do you have a copy?
d. Where did you learn about their exis- tence?
e. Have you ever tried to implement them?

I will give you a brief summary of the St Louis Voluntary Codes of Conduct so that the next few questions are clear. The St Louis Voluntary Codes of Conduct were produced by a group of nursery professionals, landscape architects, scientists, and conservationists as a way to minimize the number of invasive plants introduced by the horticulture trade. The voluntary codes for nursery professionals more or less correspond to the activities described earlier. In short, the practices suggested by the St Louis Voluntary Codes of Conduct are: evaluating and monitoring plants to determine whether they may be invasive; inter- 
acting with experts to determine which plants are invasive and to determine alternatives to invasive species; breeding for alternative plants; phasing out sales of plants that are known to be invasive; and encouraging customers to use non-invasive plants.

23. In general, which of the following factors encourage you to engage in the activities described in these voluntary codes?
a. Consumer demand
b. Cultivating a "green" business image
c. Concern for environment
d. Participation of other nurseries
e. Employee pressure
f. Prevent government regulations
g. Other

24. Does the fact that these voluntary codes exist make you more likely to engage in these activities?

25. I will mention several groups. Please rate each group on a scale from 1 to 5 , with 1 being who you think should be least responsible and 5 being the most responsible for preventing plant invasions via the horticulture trade.
a. Consumers
b. Retailers
c. Wholesalers
d. Growers
e. Policy Makers
f. Scientists
g. Government Agencies

\section{References}

Alberini A, Segerson K (2002) Assessing voluntary programs to improve environmental quality. Environ Resour Econ 22:157-184

Anderson NO (2004) Invasive horticultural crops (Part 3): who's monitoring and controlling them? Minnesota Nursery and Landscape Association. MNLA News 28(6):45-47

Animal and Plant Health Inspection Service (APHIS) (2004) Nursery stock regulations, proposed rule. Fed Regist 69(237):71736-71744

Anton WRQ, Deltas G, Khanna M (2004) Incentives for environmental self-regulation and implications for environmental performance. J Environ Econ Manage 48:632-654

ATTRA (1997) Purple loosestrife: public enemy \#1 on federal lands, vol 1, no. 2. ATTRA Interior Helper, Washington, p 2

Barbier E, Knowler D (2006) Commercialization decisions and the economics of introduction. Euphytica 148:151-164

Baskin Y (2002) The greening of horticulture: new codes of conduct aim to curb plant invasions. Bioscience 52:464-471

Bell CE, Wilen CA, Stanton AE (2003) Invasive plants of horticultural origin. Hortscience 38:14-16

Brenzel KN (ed) (2001) Sunset western garden book. 7th edn. Sunset Publications, Menlo Park

Carman HF, Rodriguez AM (2004) Economic contributions of the California nursery industry. Giannini Foundation Information Series No. 4-1. Regents of the University of California

Caton BP (2005) Availability in Florida nurseries of invasive plants on a voluntary "do not sell" list. United States Department of Agriculture, Animal and Plant Health Inspection Service, Raleigh

Center for Plant Conservation (CPC) (2006) Current list of endorsements of the voluntary codes of conduct. Available at: http://www.centerforplantconservation.org

Connick S, Gerel M (2005) Don't sell a pest: a new partnership to prevent plant invasions through horticulture. Cal-IPC News, Summer 2005, pp 4, 5, 14

D'Antonio CM, Jackson NE, Horvitz CC, Hedberg R (2004) Invasive plants in wildland ecosystems: merging the study of invasion processes with management needs. Front Ecol Environ 2:513-521

Fay K (ed) (2001) Linking ecology and horticulture to prevent plant invasions. In: Proceedings of the workshop at the Missouri botanical garden, Missouri

Fay K (ed) (2002) Linking ecology and horticulture to prevent plant invasions II. In: Proceedings of the meeting at the Chicago botanic garden, Chicago

Florida Exotic Pest Plant Council (FLEPPC) (2001) FNGA urges Florida's Nursery and Landscape Industry to Phase Out 34 Invasive Plants. Wildland Weeds 4:20-21

Gotelli NJ, Ellison AM (2004) A primer of ecological statistics. Sinauer Associates, Sunderland

Hall CR, Hodges AW, Haydu JJ (2005) Economic impacts of the green industry in the United States. Available at: www.utextension.utk.edu/hbin/greenimpact.html

Harrison K (1999) Talking with the donkey: cooperative approaches to environmental protection. J Ind Ecol 2:51-72

Hulme PE (2003) Biological invasions: winning the science battles but losing the conservation war? Oryx 37:178193

Jerardo A (2005) Floriculture and nursery crops outlooks. Electronic Outlook Report FLO-04. Economic Research Service, United States Department of Agriculture. 23 p. Available at: http://www.ers.usda.gov/ publication/floc/Sep05/FLO04.pdf 
Khanna M (2001) Non-mandatory approaches to environmental protection. J Econ Surv 15:291-324

Leung B, Lodge DM, Finnoff DA, Shogren A, Lewis MA, Lamberti G (2002) An ounce of prevention or a pound of cure: bioeconomic risk analysis of invasive species. Proc R Soc Lond B Biol Sci 269:2407-2413

Lubell M (2002) Environmental activism as collective action. Environ and Behav 34:431-454

Lubell MN (2004) Collaborative watershed management: a view from the grassroots. Policy Stud J 32:321-341

Mack RN, Erneberg M (2002) The United States naturalized flora: largely the product of deliberate introductions. Ann Mo Bot Gard 89:176-189

Mack RN, Simberloff D, Lonsdale WM, Evans H, Clout M, Bazzaz FA (2000) Biotic invasions: causes, epidemiology, global consequences, and control. Ecol Appl 10:689-710

Manzo LC, Weinstein ND (1987) Behavioral commitment to environmental protection: a study of active and nonactive members of the Sierra Club. Environ Behav 19:673-694

Massachusetts Invasive Plant Advisory Group (MIPAG) (2005) The evaluation of non-native plant species for invasiveness in Massachusetts. Available at: www.newfs.org/conserve/docs/MIPAG040105.pdf

National Invasive Species Council (NISC) (2001) Meeting the invasive species challenge: national invasive species management plan. NISC, Washington

Natural Resource Council (NRC) (2002) Predicting invasions of nonindigenous plants and plant pests. National Academy Press, Washington

Pimentel D, Lach L, Zuniga R, Morrison D (2000) Environmental and economic costs of nonindigenous species in the United States. Bioscience 50(1):53-65

Pimentel D, Zuniga R, Morrison D (2005) Update on the environmental and economic costs associated with alien-invasive species in the United States. Ecol Econ 52:273-288

Potoski M, Prakash A (2002) Protecting the environment: voluntary regulations in environmental governance. Policy Curr 11:9-11
Puth LM, Post DM (2005) Studying invasion: have we missed the boat? Ecol Lett 8:715-721

Reichard SH (1997) Prevention of invasive plant introductions on national and local levels. In: Luken JA, Theiret JA (eds) Assessment and management of plant invasions. Springer, New York

Reichard SH (2004) Conflicting values and common goals: codes of conduct to reduce the treat of invasive species. Weed Technol 18:1503-1507

Reichard SH, White P (2001) Horticulture as a pathway of invasive plant introductions in the United States. Bioscience 51:103-113

Reichard SH, White P (2003) Invasion biology: an emerging field of study. Ann Mo Bot Gard 90:64-66

Reichard SH, Schmitz DC, Simberloff D, Morrison D, Lehtonen PP, Windle PN, Chavarria G, Mezitt RW (2005) The tragedy of the commons revisited: invasive species. Front Ecol Environ 3:103-109

Rejmanek M (2000) Invasive plants: approaches and predictions. Aust Ecol 25:497-506

Rivera J, de Leon P (2004) Is greener whiter? Voluntary environmental performance of western ski areas. Policy Stud J 32:417-437

Shields M, Willits FK (2003) The growing importance of the environmental horticulture industry in the agricultural economy of the Northeastern United States. Agric Resour Econ Rev 32:259-271

Tschohl AE (2000) Invasive weeds and the horticulture trade, vol 2. Noxious Times (California Interagency Noxious Weed Coordinating Committee), pp 8-9, 12

Videras J, Alberini X (2000) The appeal of voluntary environmental programs: which firms participate and why? Contemp Econ Policy 18:449-461

Vitousek PM, D'Antonio CM, Loope LL, Rejmanek M, Westbrooks R (1997) Introduced species: a significant component of human-caused global change. N Z J Ecol 21:1-16

Wilcove DS, Rothstein D, Dubow J, Phillips A, Losos E (1998) Quantifying threats to imperiled species in the United States. Bioscience 48:607-615 